\title{
Small Intestinal, Esophageal, Colorectal, Mesenteric, and Peritoneal Gastrointestinal Stromal Tumor by AJCC v8 Stage
}

National Cancer Institute

\section{Source}

National Cancer Institute. Small Intestinal, Esophageal, Colorectal, Mesenteric, and Peritoneal Gastrointestinal Stromal Tumor by A/CC v8 Stage. NCI Thesaurus. Code C136769.

A term that refers to the staging of small intestinal, esophageal, colorectal, mesenteric, and peritoneal gastrointestinal stromal tumor (GIST), following the rules of the TNM AJCC v8 classification system. (from AJCC 8th Ed.) 